\title{
MODELO COMPUTACIONAL BASEADO EM INTERFACE CÉREBRO- COMPUTADOR PARA CLASSIFICAÇÃO DE SINAIS EEG
}

\author{
Osmar Ferreira Gomes ${ }^{1}$ \\ Oberdan Rocha Pinheiro ${ }^{2}$ \\ Alex Álisson Bandeira Santos ${ }^{3}$
}

\section{RESUMO}

Atualmente, constata-se um aumento do número de pessoas diagnosticadas com algum tipo de deficiência física. Estas pessoas passam a ter algum tipo de mobilidade reduzida. Porém, as pessoas diagnosticadas com quadros clínicos desse tipo - como esclerose lateral amiotrófica, lesão na medula espinhal ou acidente vascular cerebral, por exemplo, - têm as vias neuromusculares comprometidas. Por esse motivo, elas têm dificuldade em coordenar movimentos e esforços, afetando, assim, a locomoção. Uma das alternativas para contornar esse problema é o desenvolvimento de tecnologias que substituam parte das funções perdidas das pessoas com deficiências motoras graves. As interfaces cérebro-computador surgem como solução prática e factível para ajudar indivíduos com comprometimentos motores e neurológicos graves em suas atividades normais da vida diária. Entretanto, grande parte dessas interfaces é construída de forma isolada, possuindo estruturas próprias, impactando negativamente na capacidade de reuso, integração e extensão dessas interfaces. $\mathrm{O}$ objetivo deste ensaio, então, foi desenvolver um modelo computacional baseado em interface cérebro-computador que permita o estudo e o desenvolvimento de novas tecnologias a partir dos sinais de eletroencefalograma para ajudar os indivíduos com mobilidade reduzida. Dessa forma, poderá, por exemplo, ser construída uma cadeira de rodas inteligente para as atividades necessárias das suas vidas diárias. Empiricamente, foram feitos testes com bons resultados. Assim, uma amostra de sinais de eletroencefalograma de 106 indivíduos foi utilizada para a validação empírica do modelo computacional e a comprovação da hipótese inicial. Os resultados positivos alcançados nessa investigação evidenciaram que a arquitetura proposta é viável e passível de ser reutilizada para o desenvolvimento de interfaces cérebro-computador.

Palavras-Chave: Interface cérebro-computador. Cadeira de rodas inteligente. Eletroencefalograma.
1. Engenheiro, e-mail: fgosmar@gmail. com

2. Mestre, e-mail: oberdan. pinheiro@fieb. org.br

3. Doutor e-mail: alex.santos@fieb. org.br 


\section{INTRODUÇÃO}

O ser humano tem necessidade de interagir com o ambiente ao seu redor. Entretanto, pessoas com mobilidade reduzida acabam modificando sua rotina, passando a se ocupar com atividades pouco ativas, além de reduzirem seu desempenho físico, suas habilidades motoras e sua capacidade de coordenação. Esses efeitos não favorecem a manutenção de um estilo de vida saudável, levando essas pessoas ao isolamento social e à solidão. $\mathrm{O}$ aumento das atividades sociais voltadas para indivíduos com mobilidade reduzida, cada vez mais, revela a insuficiência funcional dos equipamentos atuais direcionados para este grupo de pessoas. Segundo Petry (2013), equipamentos tradicionais para auxílio de mobilidade, como cadeiras de rodas, muletas, bengalas e membros artificiais, têm capacidade de auxílio limitado e, em muitos casos, não são capazes de prover o auxílio necessário para indivíduos que possuam combinações de deficiências físicas, cognitivas e de percepção.

Quando uma pessoa deseja realizar um determinado movimento, é através das vias neuromusculares que o cérebro envia sinais aos músculos do corpo para realizar o movimento. Contudo, em alguns casos, essa comunicação é interrompida devido a danos provocados por doenças que danificam as vias através das quais o cérebro controla o corpo. Dentre elas, estão a Esclerose Lateral Amiotrófica (ELA),Acidente Vascular Cerebral (AVC), lesão do cérebro ou da medula espinhal, paralisia cerebral, distrofia muscular e esclerose múltipla (WOLPAW et al., 2002).

De acordo com a Organização Mundial da Saúde(OMS), existem, no mundo, um bilhão de pessoas com deficiência, representando cerca de $15 \%$ da população mundial, ou uma em cada sete pessoas. Deste número, cerca de 190 milhões de adultos sofrem dificuldades significativas de mobilidade. Estima-se que cerca de 93 milhões de crianças menores de 15 anos de idade vivem com alguma deficiência moderada ou grave. Ainda, segundo a OMS, o número de pessoas que sofrem de deficiência continuará a aumentar à medida que as populações envelhecem e com o aumento global das doenças crônicas. A Assembleia Geral das Nações Unidas (ONU) destacou que cerca de $80 \%$ das pessoas com deficiência vivem em países em desenvolvimento e reiterou a necessidade de assegurar que as pessoas com deficiência estejam incluídas em todos os aspectos do desenvolvimento (WHO, 2015).

No Brasil, a população atingida por algum tipo de deficiência é significativa. De acordo com o Instituto Brasileiro de Geografia e Estatística (IBGE), 6,2\% da população brasileira tem algum tipo de deficiência. $\mathrm{O}$ estudo mostra que $1,3 \%$ da população tem algum tipo de deficiência física e quase a metade deste total, $46,8 \%$, tem grau intenso ou muito intenso de limitações e que somente $18,4 \%$ desse grupo frequenta serviço de reabilitação (IBGE, 2014). A região Nordeste teve a maior taxa de prevalência de pessoas com pelo menos um tipo de deficiência (mental, auditiva, visual e motora): $26,3 \%$.

Embora as dificuldades de mobilidade das pessoas com comprometimentos motores e neurológicos possam ser diminuídas com o uso de cadeiras de rodas inteligentes, em alguns casos, a sua utilização de forma independente ainda é um desafio. Nos últimos anos, houve um grande avanço no desenvolvimento tecnológico das interfaces cérebro-computador, sendo estas 
cada vez mais sofisticadas. Uma dasáreas em que essas tecnologias tiveram grande aplicabilidade é a ampliação da mobilidade para pessoas com graves deficiências motoras. Segundo Faria et al. (2013), especificamente para pessoas que têm deficiência grave no seu sistema motor, aplicações baseadas em eletroencefalograma são mais indicadas.

Nesse sentido, o desenvolvimento de pesquisas que contribuam para ampliação da mobilidade dessas pessoas torna-se essencial para a sua ressocialização. $\mathrm{O}$ impacto social do uso de um sistema para auxílio à mobilidade de pessoas com comprometimentos motores e neurológicos severos seria significativo, devido ao alto número de portadores de deficiência motora existente. Esse fato justifica o interesse cada vez maior no desenvolvimento de tecnologias para auxílio à mobilidade.

O objetivo geral do artigo é desenvolver um modelo computacional baseado em interface cérebro-computador que permita o estudo e o desenvolvimento de novas tecnologias a partir dos sinais de eletroencefalograma para ajudar indivíduos com mobilidade reduzida a conduzir uma cadeira de rodas inteligente em suas atividades de vida diária.

\section{DESENVOLVIMENTO}

Através das técnicas de processamento de sinais e reconhecimento de padrões, é possível extrair informações importantes dos sinais emitidos por um processo de eletroencefalografia. Entretanto, a interpretação das diversas faixas de frequências dos sinais cerebrais de uma forma mais precisa ainda representa grandes desafios. Segundo Tehovnik, Woods e Slocum (2013), são necessários mais estudos sobre o assunto, a fim de compreender como o cérebro, por meio dos seus sinais, se comporta para que a transferência das informações a um dispositivo externo se torne mais confiável.

\subsection{Limites e possibilidades}

\section{nas investigações \\ sobre interface cérebro-computador}

Esta seção apresenta trabalhos de investigação que tratam de interfaces cérebro-computador para auxílio de pessoas com graves comprometimentos motores.

Bhattacharyya, Shimoda e Hayashibe (2016) desenvolveram uma interface cérebro-computador utilizando imaginação do movimento para controlar um sistema robótico. Nesse trabalho, foi utilizado a imaginação da mão direita e esquerda, correspondendo às direções $\mathrm{x}$ e $\mathrm{y}$, respectivamente. 14 eletrodos localizados nas regiões do córtex frontal e motor foram utilizados para capturar os sinais EEG, com uma taxa de amostragem de $128 \mathrm{~Hz}$ e um filtro passa-banda de $0,2-45 \mathrm{~Hz}$. O sistema emprega a transformada wavelet, para extração de características e um classificador: Support Vector Machine (SVM), para o reconhecimento de padrão entre os dois estados mentais (imaginação da mão direita e da esquerda). Os usuários alcançaram os seus objetivos com uma precisão média de $75 \%$. 
No trabalho de Eid, Giakoumidis e Saddik (2016), o sistema de controle da CRI é baseado no rastreamento dos olhos. Os pesquisadores preocuparam-se em auxiliar pessoas com deficiências motoras advindas de doenças, como a ELA. Os usuários tiveram uma precisão média de $70 \%$ no controle da CRI.

Edelman, Baxter e He (2016) utilizaram, para o desenvolvimento de uma interface cérebro-computador, a imaginação de quatro movimentos relacionados à mão direita: flexão, extensão, supinação e pronação. A imaginação desses movimentos foram escolhidas para representar ações complexas envolvidas no controle motor da mão, que poderia ser aplicada para o controle de dispositivos. Os dados EEG foram adquiridos a partir de 17 eletrodos, localizados nas regiões do córtex motor e parietal, com uma taxa de amostragem de $100 \mathrm{~Hz}$ e um filtro passa-banda de $2-30 \mathrm{~Hz}$. O sistema utiliza a transformada wavelet, para extração de características e um classificador Naive Bayes para o reconhecimento de padrão, a precisão apresentada foi de $82,2 \%$.

Lay e Pizarro (2015) apresentaram uma interface cérebro-computador usando o dispositivo Emotiv EEG. Nesse estudo, foi utilizado o reconhecimento de expressões faciais para controle de um robô móvel. O Emotiv EEG é um produto oferecido pela empresa Emotiv constituído por 14 eletrodos localizados nas regiões do córtex frontal e motor. Ele possui um giroscópio de dois eixos, que se comunica com o computador através da comunicação por bluetooth. O reconhecimento de padrões é realizado por um software proprietário, que pode ser processado através do Software Development Kit (SDK), e está disponível para diferentes plataformas de programação. O sistema considera cinco ações de movimento disponíveis: frente, esquerda, direita, ré e parar, cada um relacionado a um evento. Quando um evento é gerado, o Emotiv detecta um conjunto de sinais correspondente à ação determinada, por exemplo, abrir e fechar os olhos, mastigar, sorrir, pestanejar e franzir a testa. Os resultados demonstraram uma precisão média de $81 \%$ na classificação das expressões faciais.

El-Madani et al. (2015) desenvolveram uma interface cérebro-computador baseada na imaginação dos movimentos das mãos esquerda e direita, resultando em um sistema com duas classes de saída. Experimentos offline foram realizados utilizando a imaginação dos movimentos da mão esquerda/direita, para: (i) determinar as frequências ideais que deram melhor discriminação entre as classes; (ii) criar um filtro para extração de características; e (iii) treinar um classificador para medições. Nas medições online, os dados são filtrados por filtros passa-banda (obtidos a partir da análise online); em seguida, as características são extraídas utilizando o procedimento de extração de características a partir da análise online e, finalmente, o vetor de característica é classificado usando o classificador treinado. Para o processo de extração de característica, foi utilizado o algoritmo Common Spatial Patterns (CSP) e o classificador Bayes linear classifier (BLC). O sistema apresentou precisão média de $80 \%$.

O trabalho de Wang et al. (2014) consiste em uma interface que utiliza EEG com um sistema síncrono por meio do P300 (recebe esse nome por ser um potencial que surge $300 \mathrm{~ms}$ após o estímulo desencadeador). O sistema é constituído por quatro componentes, nomeadamente um sistema de aquisição de EEG, um computador principal, um módulo de comunicação e uma cadeira de rodas robótica. Os sinais de EEG são amplificados, amostrados a uma taxa de $250 \mathrm{~Hz}$ e filtrados entre 0,5 e $100 \mathrm{~Hz}$ (filtro 
passa-banda). Nesse sistema, 15 eletrodos, localizados nas regiões do córtex frontal e motor, foram utilizados para captar os sinais EEG relacionados a imaginação do movimento (mão direita e esquerda), enquanto os potenciais $\mathrm{P} 300$ são detectados a partir do piscar dos olhos, fazendo uso de mais 2 eletrodos. O objetivo deste trabalho foi testar a capacidade dos usuários em realizar tarefas de movimentação: frente, aceleração, desaceleração e deslocamento para trás. Os resultados demonstraram uma precisão média de 93\%.

A interface cérebro-computador, desenvolvida por Faria, Reis e Lau (2012), utilizou algoritmos de classificação, tais como: Naive Bayes, Rede Neural Artificial (RNA) e Máquina de Vetor de Suporte para o reconhecimento de padrões em sinais EEG baseados em expressões faciais. Experimentos foram realizados utilizando 30 indivíduos que sofrem de paralisia cerebral. Os resultados obtidos mostraram que o classificador baseado em RNA foi mais eficiente em relação aos outros métodos, permitindo melhorar os resultados em 57\%. A aquisição dos sinais EEG foi realizada a partir do uso do dispositivo Emotiv EEG, em que 14 eletrodos localizados nas regiões do córtex frontal e motor foram empregados. A taxa de amostragem utilizada foi de $128 \mathrm{~Hz}$. Os dados extraídos dos sinais EEG correspondem às seguintes expressões faciais: sorriso, piscar os olhos, piscar o olho esquerdo, piscar o olho direito e cerrar as sobrancelhas.

Observa-se que os trabalhos de investigação, de modo geral, possuem características semelhantes, como a adaptação de diferentes tipos de interfaces de controle para facilitar a interação de pessoas com diferentes tipos de deficiência. Entretanto, muitos desses projetos foram desenvolvidos de maneira isolada, sobre arquiteturas e ferramentas próprias. Como consequência, dificuldades quanto à integração, evolução, manutenção, reutilização e testes desses projetos são comuns.

Devido à relevância destes fatores, a utilização de um modelo computacional na automatização de tarefas que permita o desenvolvimento de novas interfaces cérebro-computador apresenta-se como uma iniciativa promissora, podendo viabilizar a utilização de diferentes ferramentas para que pesquisadores possam validar hipóteses em um ambiente integrado. Este trabalho de investigação procura preencher algumas destas lacunas. Neste sentido,foca-se na criação de um modelo computacional de forma a auxiliar no desenvolvimento de novas tecnologias baseadas em interface cérebro-computador, provendo vantagens quanto ao reuso, produtividade e evolução das aplicações.

\subsection{Projeto e desenvolvimento da pesquisa}

\subsubsection{Modelo computacional}

O modelo computacional, ilustrado na Figura 1 , segue o fluxo proposto por Norani, Mansor e Khuan (2010), que consiste nas etapas de aquisição e pré-processamento dos sinais, extração de características e classificação. Os sinais EEG brutos são lidos e armazenados em arquivos seguindo o formato European Data Format (EDF). Em seguida, calcula-se a Fast Fourier Transform (FFT) dos sinais EEG. O sistema de controle recebe as informações de amplitude e frequência do sinal EEG e os armazena em um vetor.Essas informações serão utilizadas na fase de treinamento e caracterização do modelo para acionamento da CRI. Os componentes do modelo computacional, especificados a seguir, têm funções específicas. 
Figura 1: Modelo computacional do projeto
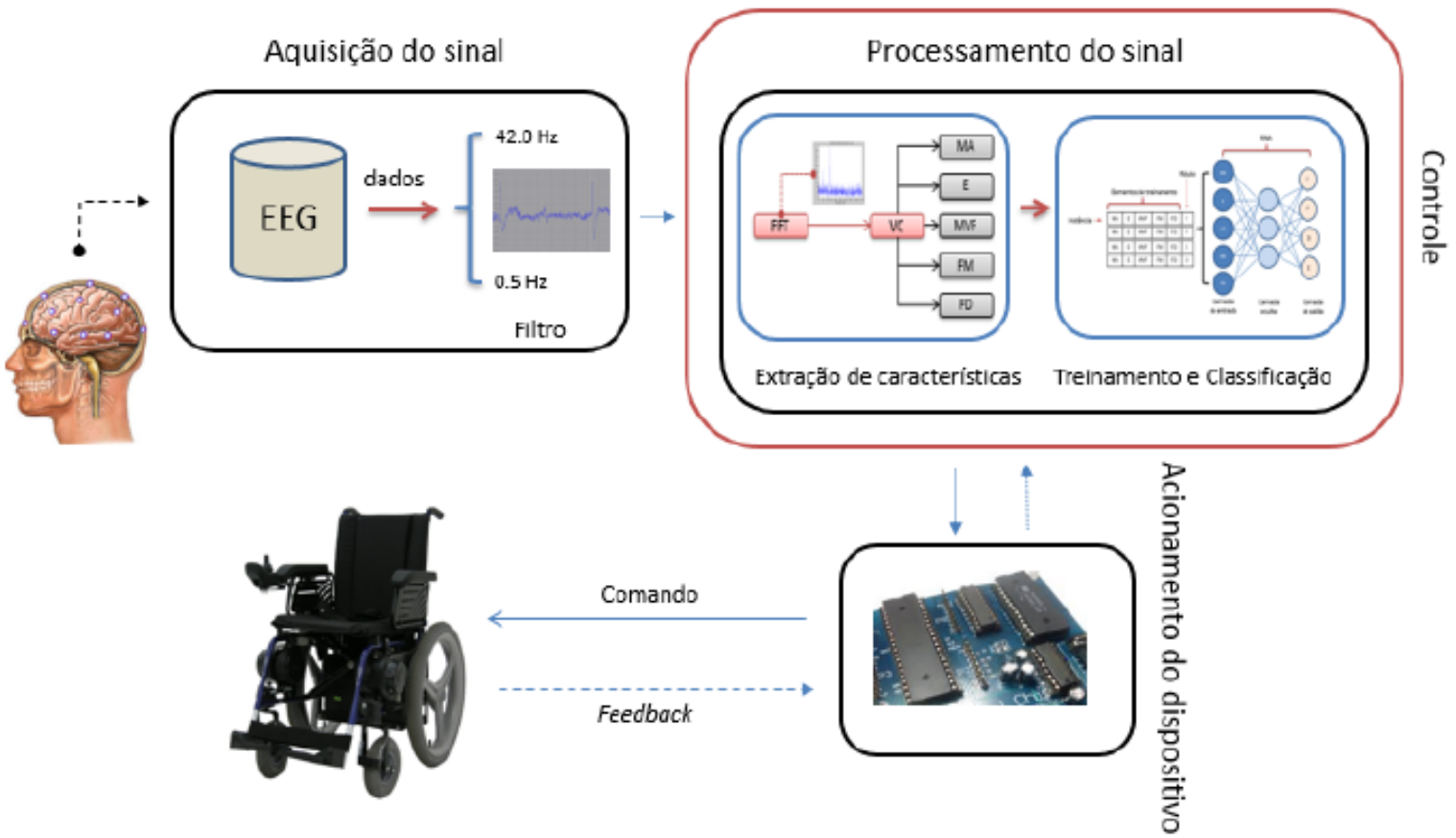

Fonte: Dos autores (2019)

\subsubsection{Módulo de aquisição do sinal}

O primeiro módulo a ser considerado foi o módulo relativo à aquisição dos dados para análise. Os sinais EEG são filtrados por um filtro digital passa-faixa, cujas frequências variam em uma faixa de 0,5 a $42 \mathrm{~Hz}$ e amostrados em uma taxa de $160 \mathrm{~Hz}$. O modelo permite a parametrização dos valores do filtro (mínimo e máximo) e taxa de amostragem, esquema ilustrado na Figura 2.

Figura 2: Esquema: aquisição do sinal

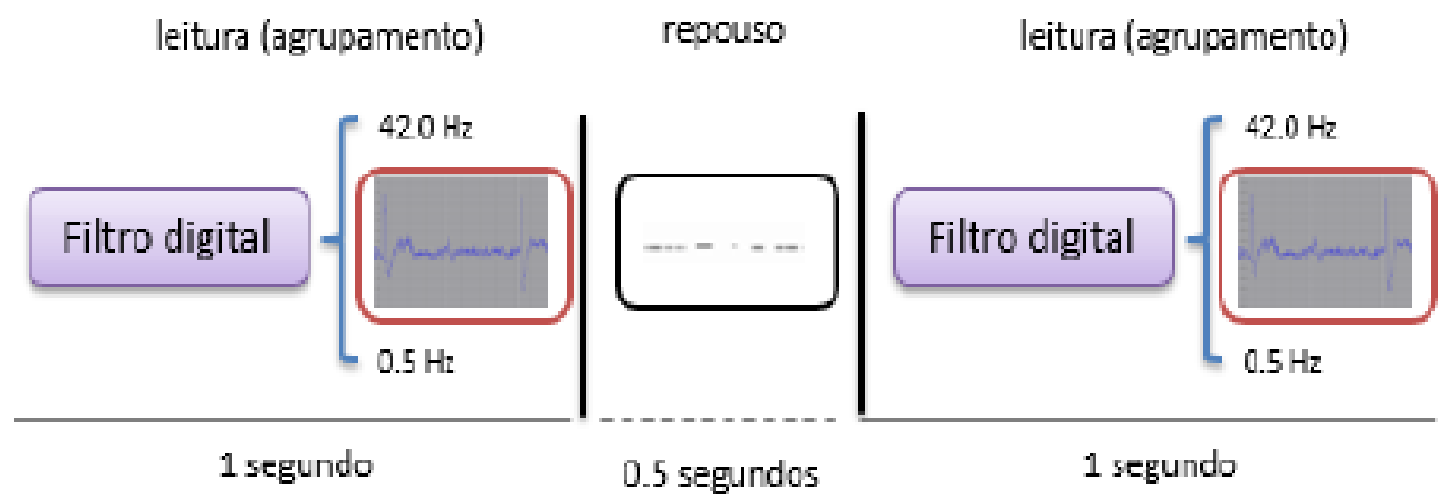

Fonte: Dos autores (2019)

Os sinais EEG filtrados são agrupados em janelas de 1 segundo, com sobreposição de 50\% (0.5 segundos). Esses registros são digitalizados e entregues ao módulo de processamento do
sinal.Para a realização do processamento digital do sinal, foi utilizada a biblioteca Java Digital Signal Processing (DSP) collection. Trata-se de um conjunto de classes open source desenvolvidas 
utilizando a linguagem de programação Java. O filtro digital passa-faixa utilizado nesse trabalho de investigação é baseado na Application ProgrammingInterface(API) presente no componente Java (DSP) collection.

\subsubsection{Módulo de processamento do sinal}

O módulo de processamento do sinal já inclui o pré-processamento aplicado ao sinal adquirido, que passa pela filtragem da faixa de interesse. Essa etapa consiste no processo de extração de características, treinamento e classificação dos dados. Após a recepção dos dados, calcula-se a FFT a partir dos dados de entrada.Para o cálculo da FFT, foi utilizada a biblioteca The Apache Commons Mathematics Library. O sistema de controle, baseado em informações de amplitude e frequência dos sinais EEG, calcula os atributos que contém os padrões de entrada para o Vetor de Características (VC), esquema ilustrado na Figura 3. O vetor de características é composto por cinco atributos, que contém o padrão a ser analisado pelo processo de treinamento e classificação do modelo. Os atributos utilizados nesse trabalho de investigação seguem o modelo definido por George e Azevedo (2007).

Figura 3: Esquema: aquisição do sinal

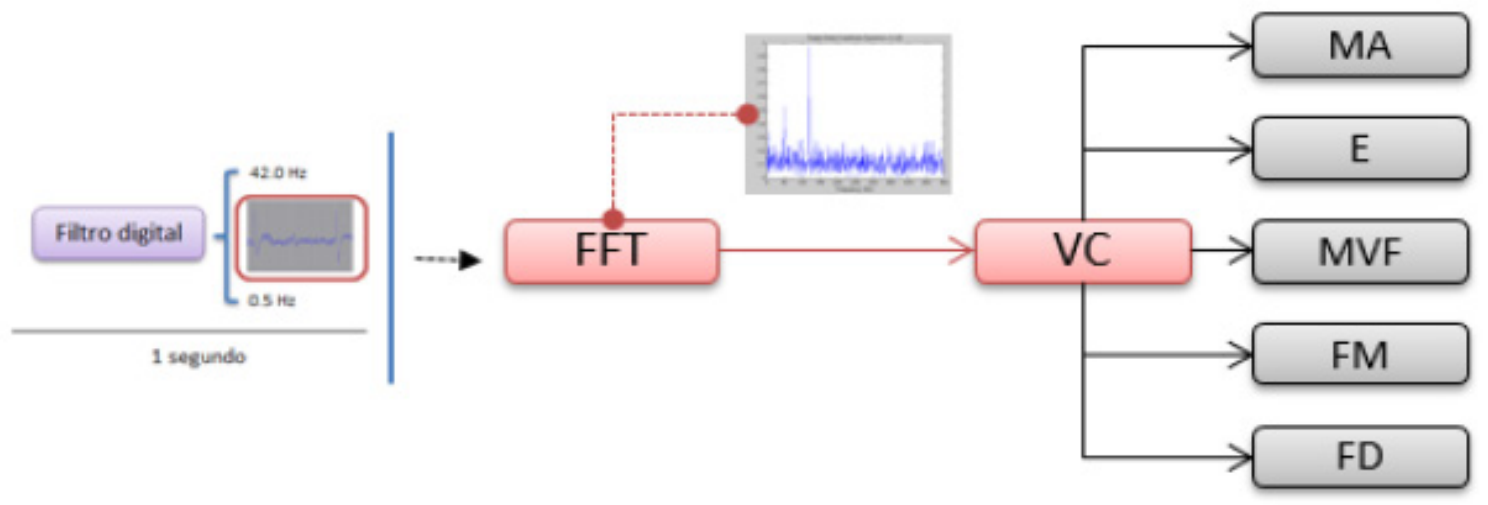

Fonte: Dos autores (2019)

Esses atributos são definidos como:

- Média aritmética (MA): representa o valor médio do sinal. $\mathrm{O}$ atributo é calculado pela Equação 1.

$$
m(s)=\frac{1}{N} \sum_{N}^{\mathrm{n}=1} S[n]
$$

Onde:

s é o valor do sinal da FFT;

$\mathbf{N}$ o tamanho do vetor de características (S).
- Energia (E): representa a área sob a curva descrita pela função do sinal elevada ao quadrado, calculado pela Equação 2.

$$
E(s)=\frac{1}{N} \Sigma_{N}^{\mathrm{n}=1}|S[n]|^{2}
$$

- Máximo valor da FFT (MVF): representa o ponto onde ocorre o máximo valor da curva da FFT, calculado pela Equação 3. 
- Mínimo valor da FFT (FM): representa o ponto onde ocorre o valor mínimo da FFT, calculado pela Equação 4.

$$
F M(s)=\min (S[n])
$$

- Frequência dominante (FD): representa a frequência que possui maior amplitude é a coordenada $\mathrm{X}$ do ponto onde ocorre o máximo valor da curva da FFT. A Figura 4 ilustra a frequência principal: $8 \mathrm{~Hz}$.

Figura 4: Frequência dominante

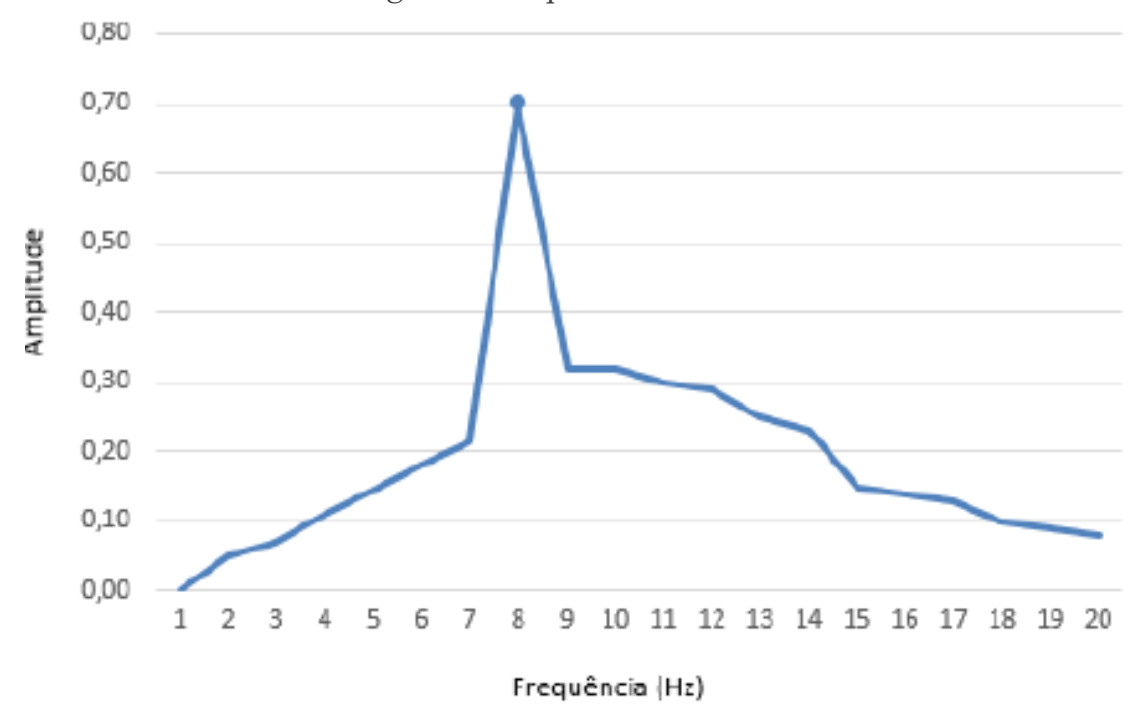

Fonte: Adaptado de George e Azevedo (2007)

O processo de classificação é realizado em duas etapas: treinamento (etapa de aprendizado) e classificação dos dados (testes). Na etapa de treinamento, o modelo do classificador é construído descrevendo um conjunto pré-determinado de classes. A Figura 5 apresenta o esquema de comportamento do processo de classificação.

Figura 5: Figura 5: Esquema: treinamento e classificação

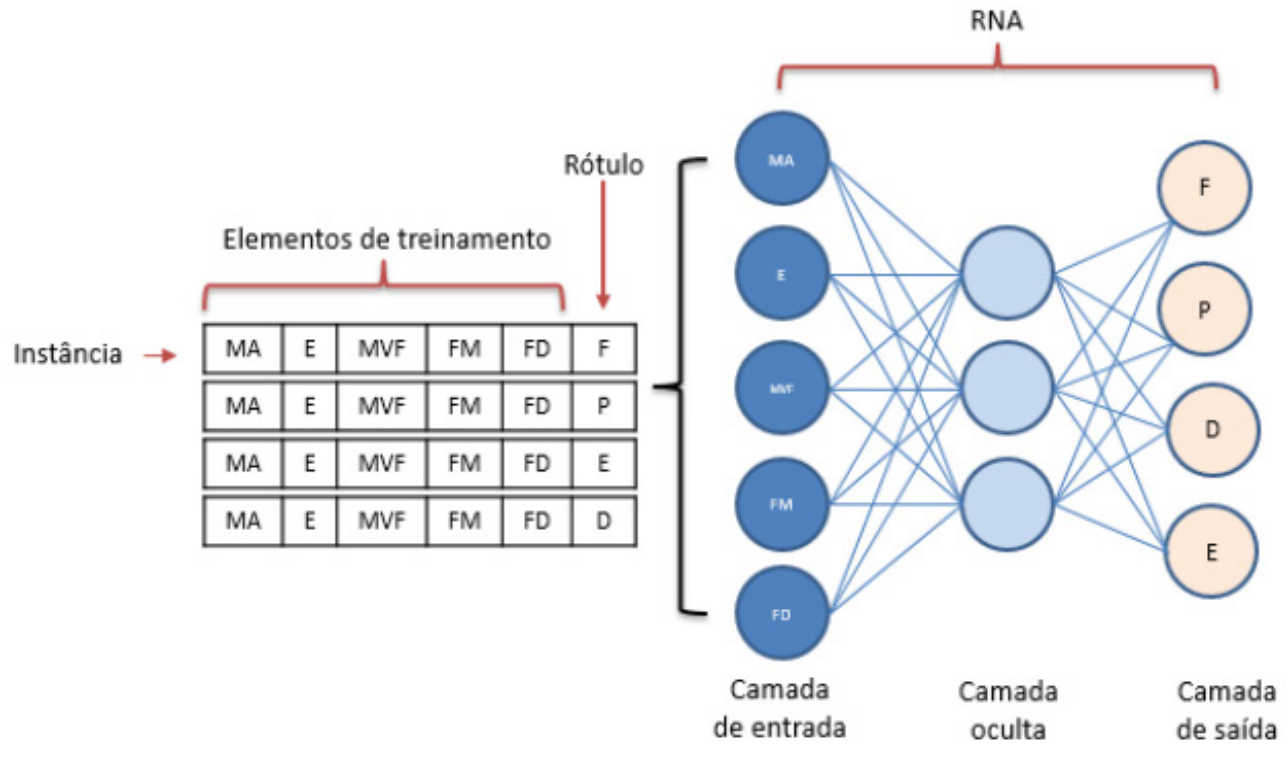

Fonte: Dos autores (2019) 
A RNA utilizada é composta por 3 camadas (entrada, oculta e saída). O número de neurônios da camada de entrada da RNA é determinado pela dimensionalidade do vetor de características, sendo cinco. A quantidade de neurônios na camada de saída da rede foi definida como quatro neurônios, visto que o objetivo da rede é descriminar entre quatro estados mentais, produzindo quatro respostas por parte da RNA, sendo: $\mathrm{F}$ (frente), $\mathrm{P}$ (parar), E (esquerda) e D (direita). Já para a definição do número de neurônios da camada oculta da RNA, utilizaremos a metodologia definida por Han e Kamber (2006), Equação 5, sendo esta a opção padrão do modelo. $\mathrm{O}$ modelo permite a parametrização da quantidade do número de neurônios da camada oculta da RNA.

$$
N_{\text {bidden }}=2 N_{\text {in }}+1
$$

Onde:

$\mathrm{N}_{\text {in }}$ é o número de neurônios da camada de entrada;

$\mathrm{N}_{\text {hidden }}$ representa o número de neurônios da camada oculta.

Dessa forma, o sistema de controle extrai os atributos do vetor de características (MA, E, MVF, FM e FD) para realizar o treinamento da RNA, ou seja, construir o modelo da RNA através do conjunto de dados de treinamento. Aos elementos de treinamento são associados rótulos de classes às quais cada um pertence (E, D, F e P). Esta etapa é conhecida como aprendizagem supervisionada, pois o rótulo da classe de cada elemento de treinamento é fornecido ao classificador.

No modelo, a RNA será treinada, através de exemplos, para classificar uma determinada imaginação de movimento. A saída dessa RNA indicará o comando de movimentação da CRI (Tabela 1).

Tabela 1: Comando de movimentação da CRI

\begin{tabular}{|c|c|c|}
\hline Saída da RNA & Imaginação do movimento & Direção (CRI) \\
\hline E & Punho esquerdo & Esquerda \\
\hline D & Punho direito & Direita \\
\hline F & Ambos os punhos & Frente \\
\hline P & Ambos os pés & Parar \\
\hline
\end{tabular}

Fonte: Dos autores (2019)

Os sinais dos registros EEG utilizados para formatação dos elementos de treinamento foram adquiridos através do banco de dados eegmmidb - EEG Motor Movement/Imagery Dataset, capturado utilizando o sistema BCI2000 (SCHALK et al., 2004), disponível através do PhysioBank (GOLDBERGER et al.,2000). Este banco de dados é composto por mais de 1500 registros de um e dois minutos de sinais EEG obtidos a partir de 109 voluntários, sendo quarenta e três pessoas do sexo masculino e sessenta pessoas do sexo feminino, com idade entre 19 e 67 anos de idade. Dados de seis indivíduos não foram disponibilizados para determinação do sexo. Os indivíduos não tinham distúrbios neurológicos e não foram 
treinados anteriormente para a utilização da interface cérebro-computador. A população de voluntários foi extraída dos funcionários do Departamento de Saúde do Estado de Nova York. Os indivíduos tinham concluído o ensino médio e a maioria tinha completado quatro anos de ensino superior.

\subsubsection{Módulo de acionamento do dispositivo}

A primeira etapa do processo de adaptação da cadeira de rodas foi o desenvolvimento do módulo de acionamento do dispositivo. Por se tratar de um equipamento comercial, não foi possível compreender o módulo de potência para acionamento, uma vez que o fabricante não fornece esse tipo de informação. Sendo assim, para desenvolver o circuito que simula o joystick original da cadeira de rodas foi necessário entender quais os valores de tensão específicos, responsáveis por realizar os movimentos na cadeira de rodas através do joystick.

O joystick da cadeira de rodas (Freedom Carbon) envia sinais para um circuito embarcado que, de acordo com o movimento executado na alavanca do dispositivo, dois sinais de tensão são enviados ao circuito do microcontrolador, que, por sua vez, interpreta e envia outros sinais ao sistema de motorização da cadeira de rodas para realizar os movimentos desejados. A Figura 6 ilustra o circuito do microcontrolador, destacando-se o Programmable Interface Controller (PIC) e barramento, de onde são enviados os sinais do joystick diretamente ao circuito.

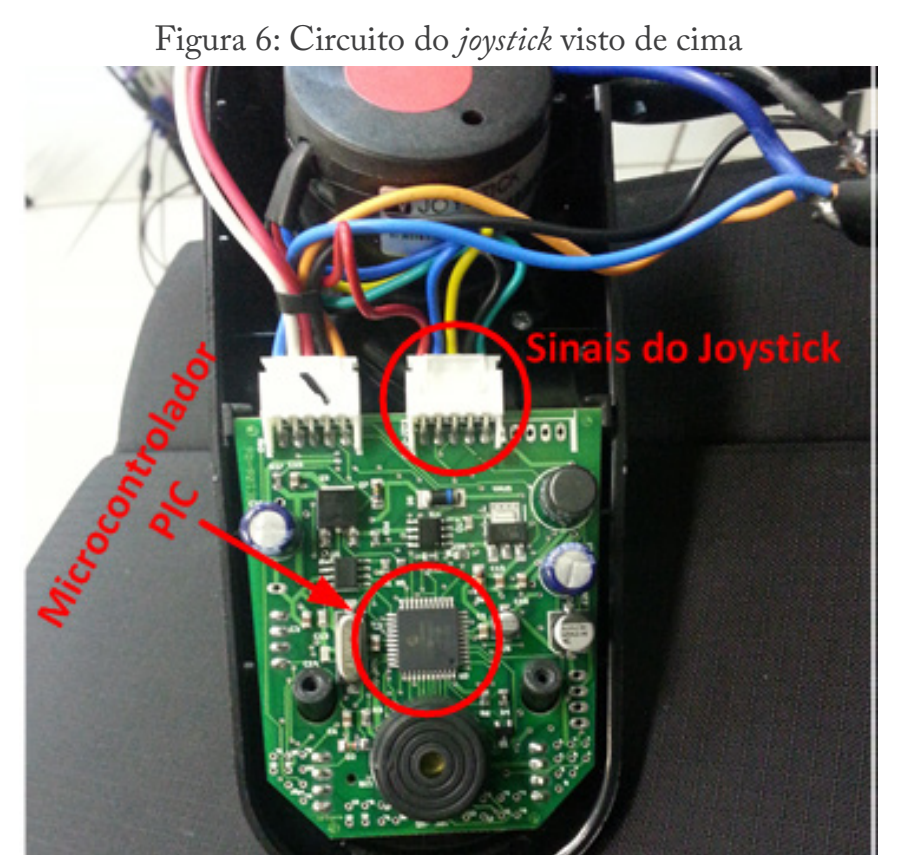

Fonte: Freedom (2012)

Sendo assim, desenvolvemos um circuito que realiza a mesma função do joystick, enviando tensões analógicas ao circuito do microcontrolador para controlar os movimentos da cadeira de rodas. Em resumo, o circuito simula em sua saída os mesmos sinais analógicos do joystick original da cadeira de rodas, consistindo em uma adaptação do circuito já existente. 
Pode-se observar,na Figura 7, um esquema com os fios de ligação no circuito do microcontrolador, destacando os barramentos provenientes do conector canon (A) e do joystick (B) e seus respectivos valores de tensão, medidos por um multímetro digital.

Figura 7: Esquema de ligação entre o joystick e o circuito do microcontrolador

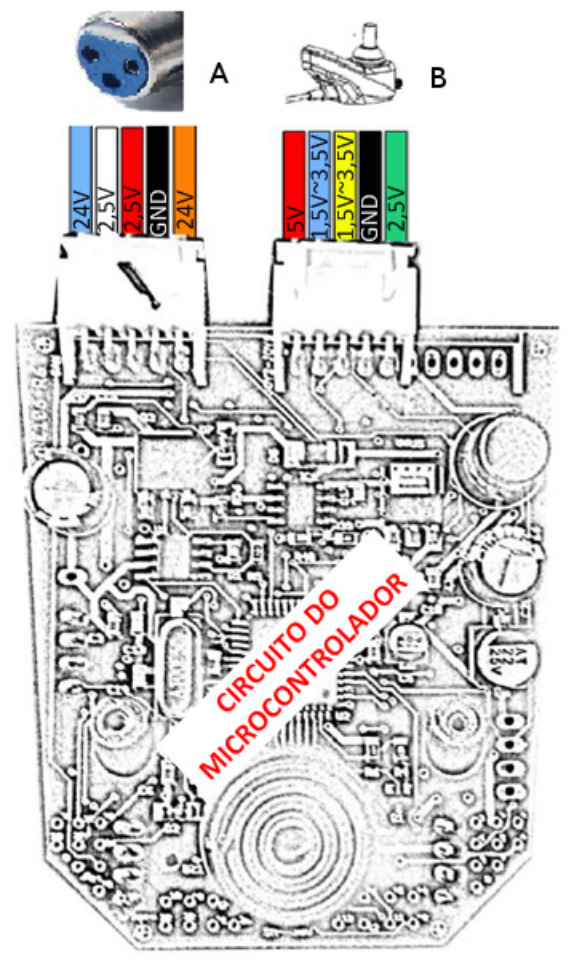

Fonte: Dos autores (2019)

O fio azul proveniente do joystick (B) controla as ações de movimentos: frente ou ré; enquanto o fio amarelo controla as ações de movimentos: esquerda ou direita. Para cada movimento, foram realizadas medidas nas tensões de cada fio com o auxílio de um multímetro digital.
A Tabela 2 apresenta os respectivos valores de tensão dos fios do barramento controlado pelo joystick. Assim, entende-se de que forma esses valores alteram o movimento da cadeira de rodas.

Tabela 2: Tensão dos fios do barramento controlado pelo joystick e os movimentos

\begin{tabular}{|l|c|c|c|c|c|}
\cline { 2 - 6 } \multicolumn{1}{c|}{} & Parado & Direita & Esquerda & Frente & Ré \\
\hline Fio Azul & $2,5 \mathrm{~V}$ & $2,5 \mathrm{~V}$ & $2,5 \mathrm{~V}$ & $3,5 \mathrm{~V}$ & $1,5 \mathrm{~V}$ \\
\hline Fio Amarelo & $2,5 \mathrm{~V}$ & $1,5 \mathrm{~V}$ & $3,5 \mathrm{~V}$ & $2,5 \mathrm{~V}$ & $2,5 \mathrm{~V}$ \\
\hline
\end{tabular}

Fonte: Dos autores (2019)

Nota-se que é possível controlar os movimentos da cadeira de rodas, variando os valores de tensão aplicados nos fios azul e amarelo localizados no barramento proveniente do joystick (Figura 9). Dessa forma, com a implementação de um circuito capaz de enviar sinais analógicos para 
esses pinos, pode-se movimentar a cadeira de rodas. $\mathrm{O}$ circuito que simula as ações do joystick original deve ser projetado respeitando-se os limites operacionais das tensões a serem enviadas ao circuito do microcontrolador da cadeira de rodas, evitando, assim, que ocorra o impedimento de movimento por conta de uma tensão enviada fora da faixa de operação.

\subsection{Avaliação e resultados experimentais}

Nesta seção, será apresentado o experimento computacional realizado para avaliar o comportamento da interface cérebro-computador, relacionado ao desempenho da RNA, interface de acionamento e integração dos módulos e componentes do sistema. A arquitetura do sistema utiliza a técnica de Validação Cruzada (10-fold cross-validation) para a validação da RNA do tipo Multi Layer Perceptron (MLP), com o algoritmo de retropropagação do erro (backpropagation).
Os sinais dos registros bEEG utilizados para validar a interface cérebro-computador foram adquiridos através do banco de dados eegmmidb - EEG Motor Movement/Imagery Dataset, capturado utilizando o sistema BCI2000 (SCHALK et al., 2004), disponível através do PhysioBank (GOLDBERGER et al., 2000). Este banco de dados é composto por mais de 1500 registros de sinais EEG, obtidos a partir de 109 voluntários. Os registros de 106 voluntários foram utilizados nos testes. Dados de 3 voluntários apresentaram problemas na etapa de aquisição, motivo pelo qual tais registros não foram considerados. Neste trabalho de investigação, foram utilizados apenas os eletrodos posicionados na região do córtex pré-frontal (Fp1), ilustrados na Figura 8.

O computador utilizado foi um DELL modelo Latitude E6430, com processador Intel R CORETM i7-3540M -3.00GHz 2 núcleos e 4 threads, placa de vídeo NVidia R NVS TM 5200M - 1GB, 64bit - memória RAM com capacidade para 8GB e sistema operacional Linux Ubuntu 14.04.2 LTS.

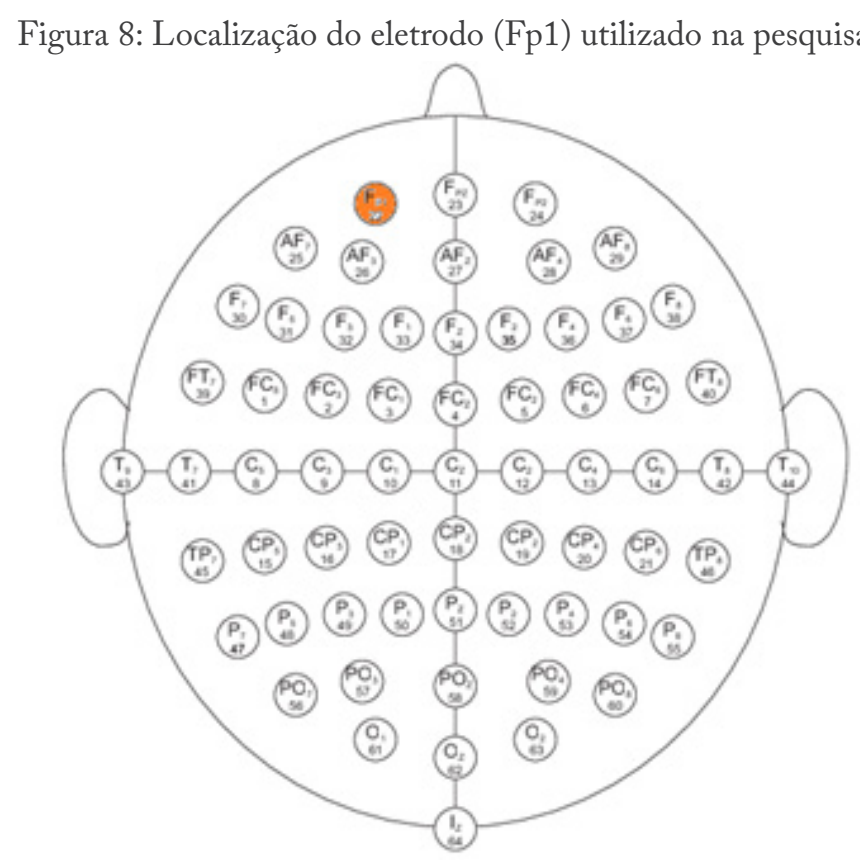

Fonte: Adaptado de Goldberger et al. (2000) 
A coleta dos registros foi realizada com a utilização de um filtro digital passa-faixa, cujas frequências variam em uma faixa de 0.5 a 42.0 $\mathrm{Hz}$ e frequência de amostragem de $160.0 \mathrm{~Hz}$.A RNA foi configura com 5 neurônios na camada de entrada, 11 neurônios na camada oculta e 4 neurônios na camada de saída. Foram simuladas combinações do parâmetro taxa de aprendizagem $(0.01,0.1,0.5,0.9)$ e da constante de momentum $(0.0,0.1,0.5,0.9)$ para observar o efeito da convergência da RNA. Cada combinação foi treinada até 1000 épocas. Para avaliação da RNA,foram selecionadas 28.614 instâncias dos dados originados do eletrodo Fp1. A Figura 9 apresenta as melhores curvas de aprendizagem para cada combinação taxa de aprendizagem $\mathrm{x}$ constante de momentum, para determinar a melhor curva de aprendizagem global.

Observa-se, a partir da Figura 9, que o melhor parâmetro da taxa de aprendizado foi $\eta=0.1 \mathrm{e}$ a constante de momentum foi $\alpha=0.1$. Nesse contexto, o fato de o erro médio quadrado da curva não variar muito, sugere que os parâmetros são os mais adequados para esse problema. Nesse contexto, a RNA final foi avaliada para determinar a sua precisão e capacidade de generalização. Os parâmetros da taxa de aprendizado $=0.1$, constante de momentum 0.1 e número de épocas $=1000$, foram definidos para esse experimento. O mesmo conjunto de dados com 28.614 instâncias usados anteriormente foram utilizados novamente.

Figura 9: Melhores curvas de aprendizagem selecionadas (eletrodo Fp1)

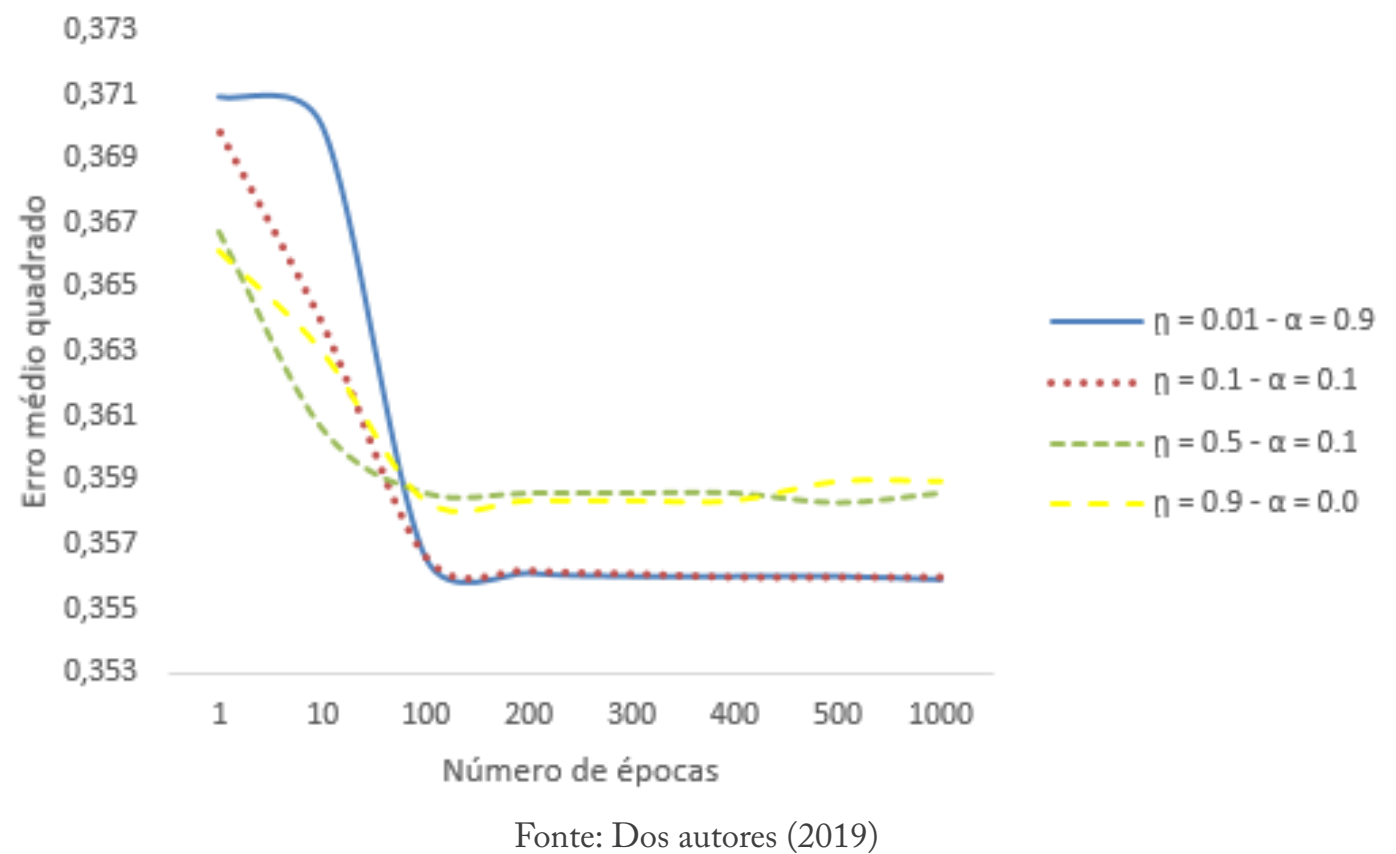

Findo o experimento, a RNA demonstrou uma precisão média de 50,40\% e um percentual de instâncias classificadas corretamente igual a 50,77\%. O número de instâncias classificadas corretamente foi de 14527 , contra 14087 instâncias classificadas incorretamente. Ao analisarmos a matriz de confusão (Tabela 3), observa-se, que a classe E (imaginação de movimento do punho esquerdo) obteve 3571 instâncias classificadas corretamente, contra 3647 instâncias classificadas incorretamente. A classe D (imaginação de movimento do punho direito) obteve 1264 instâncias classificadas corretamente, contra 5822 instâncias classificadas incorretamente. A classe F (imaginação de movimento de ambos os punhos) obteve 7149 
instâncias classificadas corretamente, contra 15 instâncias classificadas incorretamente. Já à classe $\mathrm{P}$ (imaginação de movimento de ambos os pés) obteve 2543 instâncias classificadas corretamente, contra 4603 instâncias classificadas incorretamente.

Figura 10: Matriz de confusão da classificação dados (eletrodo Fp1).

\begin{tabular}{|c|c|c|c|c|}
\hline \multicolumn{5}{|c|}{ Dados da amostragem } \\
\hline Classes & E & D & F & P \\
\hline E & 3571 & 1281 & 20 & 2346 \\
\hline D & 3448 & 1264 & 30 & 2344 \\
\hline F & 3 & 2 & 7149 & 10 \\
\hline P & 3235 & 1342 & 26 & 2543 \\
\hline
\end{tabular}

Fonte: Dos autores (2019)

O método apresentou uma precisão de 98,9\% para a classe F (Tabela 3), ou seja, a RNA demostrou boa capacidade de classificação correta para o estado mental relacionado à imaginação de movimento de ambos os punhos, seguida das classes P $(35,1 \%)$, E (34,8\%) e D $(32,5 \%)$. Consequentemente, a classe $\mathrm{D}$ apresentou alta taxa de confusão, em que 3448 instâncias foram consideradas como E, 2344 instâncias foram consideradas como P e 30 instâncias foram consideradas como F.

A Figura 10 ilustra como poderia ser possível acionar a CRI a partir de 4 estados mentais: imaginação de movimento do punho esquerdo, direito, ambos os punhos e ambos os pés para acionar uma CRI nas direções: esquerda, direita, frente e parar.

Figura 11: Esquema para acionar CRI a partir de 4 estados mentais

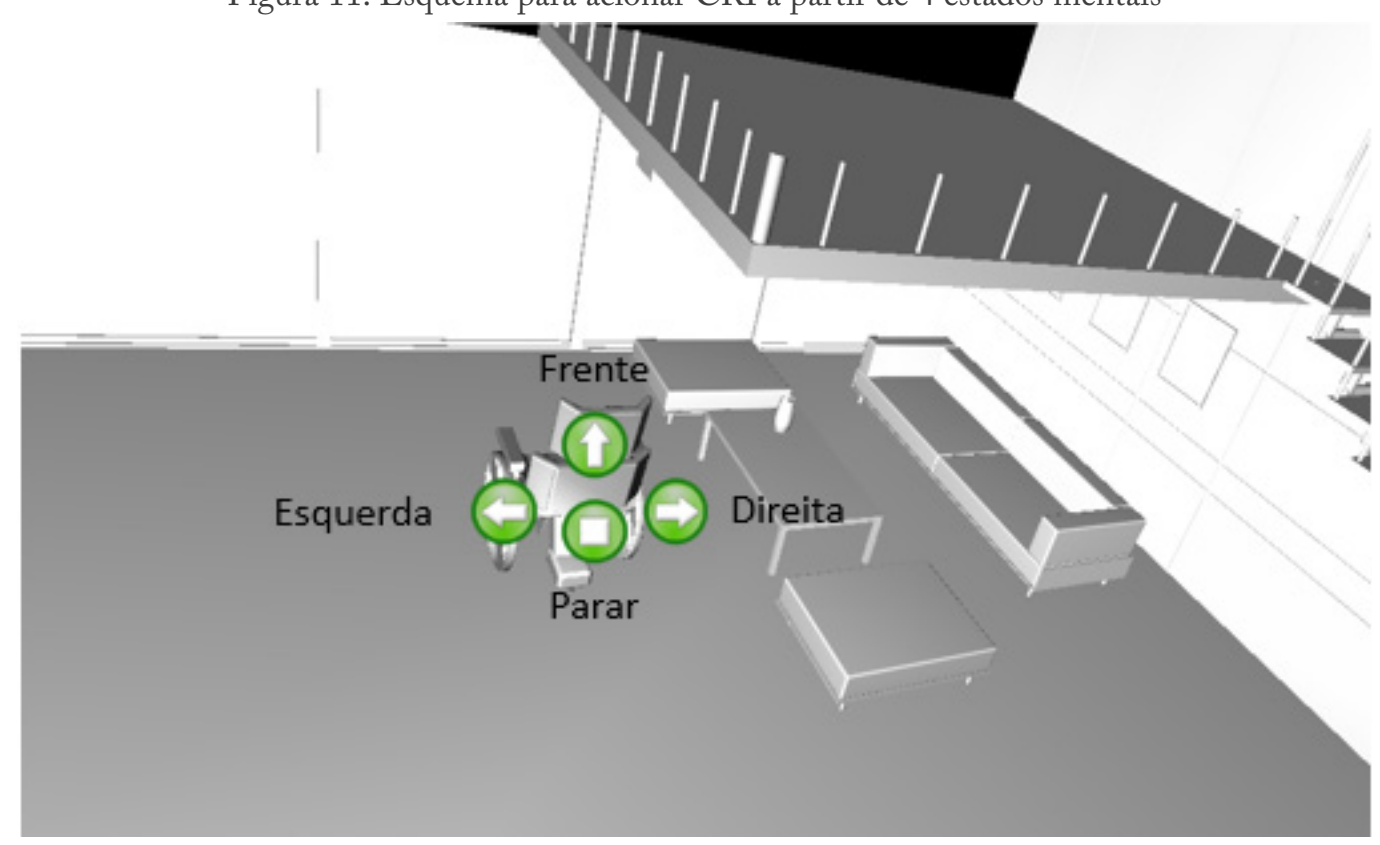

Fonte: Dos autores (2019) 
A Figura 11 ilustra o ambiente do experimento preparado para validação da integração da interface cérebro-computador com a CRI.Nesse experimento, a integração entre os módulos do sistema foi testada. Dados dos sinais EEG de 5 indivíduos $(055,069,081,095$ e 102) foram selecionados de maneira aleatória. $\mathrm{O}$ método de teste envolveu os seguintes procedimentos:

- filtrar os dados relacionados à imaginação de movimentos do punho esquerdo, amostrados em uma taxa de $160 \mathrm{~Hz}$ (apenas 1 segundo de coleta);

- aplicar a FFT sobre os dados;

- criar o vetor de características;
- classificar os dados através do resultado da saída da RNA.

- acionar a CRI com o valor de saída da RNA.

O framework JUnit e a IDE (Integrated Development Environment) Eclipse foram utilizados para a criação e execução da suíte de teste. A Figura 12 ilustra o resultado da execução do caso de teste "validar integração do sistema”. O método testado apresentou sucesso. Assim,conclui-se que os métodos apresentaram sucesso, ou seja, a partir dos testes, não foram encontradas falhas provenientes da integração interna dos componentes do sistema.

Figura 12: Abordagem para executar e avaliar o teste de integração

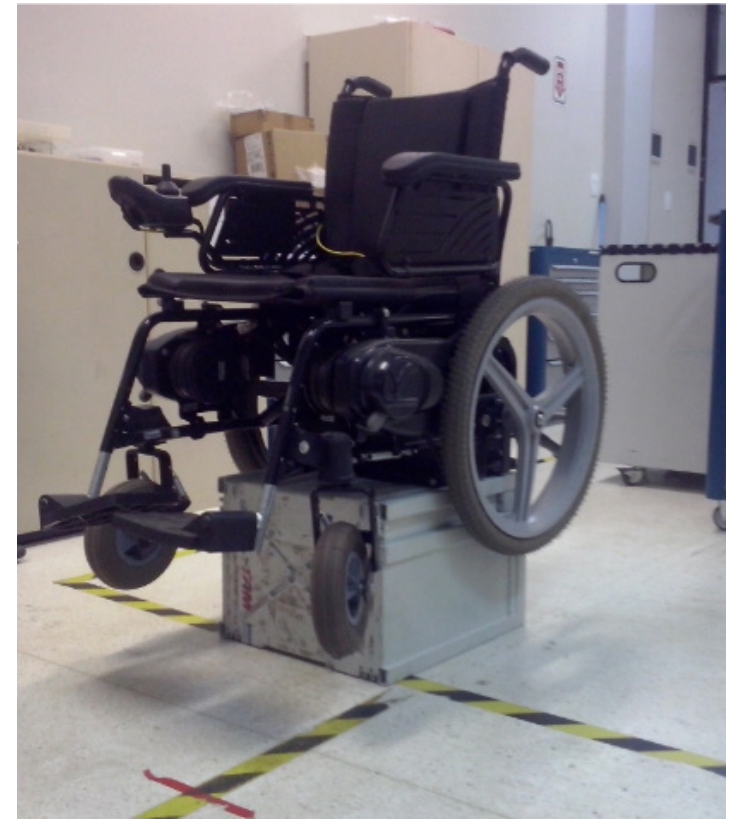

Fonte: Dos autores (2019)

Figura 13: Resultado do teste de integração do sistema

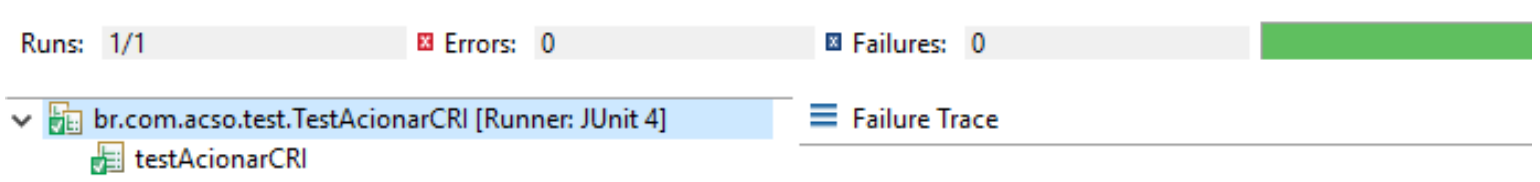

Fonte: Dos autores (2019) 
Após a conclusão dos experimentos, de acordo com os resultados, observa-se que a RNA apresentou precisão média de 50,40\% para dados do eletrodo Fp1 no processo de reconhecimento de padrões a partir dos sinais EEG imaginados do punho direito, punho esquerdo, ambos os punhos e ambos os pés. Foi possível observar, ainda, que, a RNA demostrou boa capacidade de classificação correta para o estado mental relacionado à imaginação de movimento de ambos os punhos. Apresentando 98,9\% de precisão para o eletrodo Fp1. Os dados relacionados à imaginação de movimento do punho direito apresentaram pior desempenho: $32,5 \%$ de precisão. Observa-se, a partir dos resultados, que é possível reconhecer padrões nos sinais EEG originados no córtex pré-frontal. Esse fato sugere a possibilidade de pessoas com mobilidade reduzida, através da imaginação de movimentos, poder acionar uma CRI.

\section{CONCLUSÃO}

A interface cérebro-computador proposta nesta pesquisa, através dos experimentos realizados, mostrou ser possível identificar nos sinais EEG a partir do eletrodo $\mathrm{Fp} 1$ localizado na região do córtex pré-frontal,características que expressem a intenção de quatro movimentos para acionar uma CRI.

A capacidade do sistema proposto em discernir entre quatro intenções de movimentos foi avaliada nos experimentos, conforme detalhado na Seção 2.3.A RNA apresentou precisão média de 50,40\% para dados do eletrodo Fp1 e demostrou boa capacidade de classificação correta para o estado mental relacionado à imaginação de movimento de ambos os punhos, com 98,9\% de precisão. Os dados relacionados à imaginação de movimento do punho direito apresentou pior desempenho: $32,5 \%$ de precisão. Dessa forma, a interface cérebro-computador baseado nos resultados mostrou-se útil para reconhecer padrões a partir de sinais EEG e acionar uma cadeira de rodas. Para a navegação da cadeira de rodas, grande autonomia é atribuída a CRI, cujo sistema integrado, equipado com vários sensores, é capaz de executar uma navegação segura em um ambiente semiestruturado. As técnicas desenvolvidas nesta pesquisa são promissoras, visto que o sistema destina-se a contribuir como completo na ampliação da mobilidade de pessoas com graves comprometimentos motores. Uma fase experimental mais longa com pessoas deficientes faz-se necessária, com o objetivo de uma avaliação mais completa.

Como proposta de atividade futura desta pesquisa, uma questão importante a ser tratada é o desenvolvimento do sistema de navegação e controle da CRI em ambientes indoor. A abordagem adotada para a implementação do sistema de navegação será baseada em Souza et al. (2015), adaptando-a às necessidades do projeto de pesquisa envolvendo a cadeira de rodas inteligente. Outra proposta de atividade futura seria a realização de testes em pessoas com graves deficiências motoras para melhorar a confiabilidade dos resultados. Dessa forma, mais experimentos com pessoas deficientes será de grande valor na continuidade do desenvolvimento da interface cérebro-computador e na ampliação da base de dados para treinamento do classificador. 
COMPUTATIONAL MODEL BASED ON BRAINCOMPUTER INTERFACE FOR CLASSIFICATION OF EEG SIGNS

\section{REFERÊNCIAS}

BHATTACHARYYA, S.; SHIMODA, S.; HAYASHIBE, M. A synergetic brain-machine interfacing paradigm for multi-dof robot control. IEEE Transactions on Systems, Man, and Cybernetics: Systems, v. 46, n. 7, p. 957 - 968, July 2016. ISSN 2168-2216.

EDELMAN, B. J.; BAXTER, B.; HE, B. EEG source imaging enhances the decoding of complex right-hand motor imagery tasks. IEEE Transactions on Biomedical Engineering, v. 63, n. 1, p. 4 - 14, Jan 2016. ISSN 0018-9294.

EID, M. A.; GIAKOUMIDIS, N.; SADDIK, A. E. A novel eye-gaze-controlled wheelchair system for navigating unknown environments: Case study with a person with als. IEEE Access, v. 4, p. 558 573, 2016. ISSN 2169-3536.

EL-MADANI, A.; SORENSEN, H. B.; W., K. T.; THOMSEN, C. E.; PUTHUSSERYPADY, S. Real-time brain computer interface using imaginary movements. EPJ Nonlinear Biomedical Physics, v. 9, n. 3, 2015.

FARIA, B. M.; REIS, L. P.; LAU, N. Cerebral palsy EEG signals classification: Facial expressions and thoughts for driving an intelligent wheelchair. In: 2012 IEEE 12th International Conference on Data Mining Workshops. [S.1.: s.n.], 2012. p. 33 40. ISSN 2375-9232.

KEYWORDS: Brain-

Computer Interface.

Intelligent wheelchair.

Electroencephalography. 
FARIA, B. M.; REIS, L. P.; LAU, N.; SOARES, J. C.; VASCONCELOS, S. Patient classification and automatic configuration of an intelligent wheelchair. In: __. Agents and Artificial Intelligence:

4th International Conference, ICAART 2012, Vilamoura, Portugal, February 6-8, 2012. Revised

Selected Papers. Berlin, Heidelberg: Springer Berlin Heidelberg, 2013. p. 268 - 282. ISBN 978-3-642-36907-0.

FREEDOM. FREEDOM CARBON: Manual do proprietário. Porto Alegre, 2012. 24 p.

GEORGE, A.; AZEVEDO, F. M. Identificação automática de complexos $\mathrm{k}$ e fusos do sono em sinais de EEG utilizando redes neurais e transformada wavelet. In: Anais do 8 Congresso Brasileiro de Redes Neurais. Florianópolis: SBRN, 2007. p. 1 - 6.

GOLDBERGER, A. L. et al. Physiobank, physiotoolkit, and physionet. Circulation, American Heart Association Journals, v. 101, n. 23, p. e215 e220, 2000. ISSN 0009-7322.

HAN, J.; KAMBER, M. Data Mining: Concepts and Techniques. USA: Morgan Kaufmann, 2006.

IBGE. Pesquisa nacional de saúde: 2013: percepção do estado de saúde, estilos de vida e doenças crônicas: Brasil, grandes regiões e unidades da federação. Rio de Janeiro: [s.n.], 2014. ISBN 9788524043345.

LAY, S. M.; PIZARRO, D. A. Robotic motion control with cognitive and facial detection via emotiv EEG. Ingeniare. Revista chilena de ingeniería, scielo, v. 23, p. 496 - 504, 10 2015. ISSN 0718-3305.

NORANI, N. A. M.; MANSOR, W.; KHUAN, L. Y. A review of signal processing in brain computer interface system. In: Biomedical Engineering and Sciences (IECBES), 2010 IEEE EMBS Conference on. [S.1.: s.n.], 2010. p. 443 - 449.
PETRY, M. R. A Vision-based Approach Towards Robust Localization for Intelligent Wheelchairs. Doctor in Informatics Engineering. University of Porto, Porto, 2013.

SCHALK, G.; MCFARLAND, D. J.; HINTERBERGER, T.; BIRBAUMER, N.; WOLPAW, J. R. Bci2000: a general-purpose braincomputer interface (bci) system. IEEE Transactions on Biomedical Engineering, v. 51, n. 6, p. 1034 1043, June 2004. ISSN 0018-9294.

SOUZA, J. R. de; $M^{\prime} R C^{\wedge}$ eS, R. S. M. R. C.; PINHEIRO, O. R.; oES, M. A. C. S. Bahiart@ home 2016 team description paper. In: ROBOCUP FEDERATION. Proceedings of RoboCup 2015. Hefei, China, 2015.

TEHOVNIK, E.; WOODS, L.; SLOCUM,W. Transfer of information by BMI. Neuroscience, $\mathrm{v}$. 255, p. 134 - 146, 2013. ISSN 0306-4522.

WANG, H.; LI, Y.; LONG, J.; YU, T.; GU, Z. An asynchronous wheelchair control by hybrid eegeog braincomputer interface. Cognitive Neurodynamics, v. 8, n. 5, p. 399409, 2014.

WHO. WHO global disability action plan 20142021. Better health for all people with disability. Switzerland. [s.n.], 2015. ISBN 9789241509619.

WOLPAW, J.; BIRBAUMER, N.; MCFARLAND, D.; PFURTSCHELLER, G.; VAUGHAN, T. Braincomputer interfaces for communication and control. Clinical Neurophysiology, v. 113, n. 6, p. 767 - 791, 2002. ISSN 1388-2457.

Data de recebimento: 22/05/2019

Data de aprovação: 28/08/2019 


\section{SOBRE OS AUTORES}

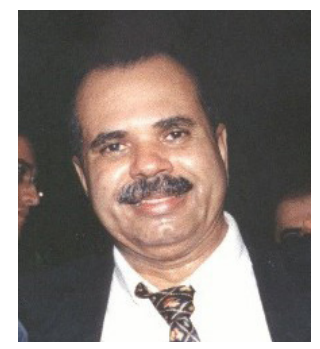

\section{Osmar Ferreira Gomes}

Estudou Engenharia

Elétrica na Universidade

Federal da Bahia (1979).

Atualmente está cursando (em fase de conclu-

são) Modelagem Computacional e Tecnologia Industrial no Centro Universitário SENAI CIMATEC. Atua desde 1978 como Professor do Curso Técnico da Escola de Engenharia EletroMecânica da Bahia e desde 2000 como Professor do Curso de Engenharia de Agrimensura da Escola de Engenharia de Agrimensura.

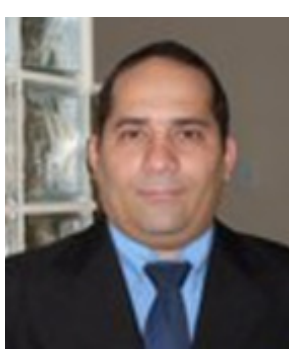

\section{Oberdan Rocha}

Pinheiro

Doutor e Mestre em Modelagem Computacional e Tecnologia Industrial pelo SENAI CIMATEC, Especialista em Sistemas Distribuídos pela Universidade Federalda Bahia-UFBA.Atualmente éProfessor Adjunto do Centro Universitário SENAI CIMATEC.Tem experiência naárea de Engenharia da Computação e Automação Industrial,com ênfase em Inteligência Artificial e Robótica.

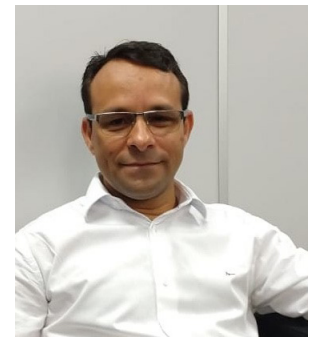

\section{Alex Álisson Bandeira Santos}

Doutor pelo Programa de Energia e Ambiente do Centro Interdisciplinar de Energia e Ambiente (CiEnAm) da Universidade Federal da Bahia (2010). Mestre em Engenharia Mecânica pela Universidade Estadual de Campinas (2001) e Graduação em Engenharia Mecânica pela Universidade Federal da Bahia (1998). Atualmente é Professor e Pesquisador do SENAI CIMATEC e Membro Sênior da Associação Brasileira de Engenharia e Ciências Mecânicas (ABCM). 